\title{
Hepaticarum species novae et minus cognitae nipponenses IV $^{*}$
}

\author{
auctore
}

\section{Sinsuke Hattori}

Received October 5, 1943.

22) Bazzania albicans Stephani in Hedwigia XXXII, 204 (1893). Fig. 21.

Mastigobryum albicans Stephani ex Ishiba in Bot. Mag. Tokyo XXI, 45 et 280 (1907), nom. nud.; Stephani, Spec. Hepat. III, 465 (1908).

Planta mediocris, flavo-virens, in aetate brunnescens, dense depressocaespitosa. Caulis olivaceus vel brunneolus, ad $5 \mathrm{~cm}$ longus, $0.3 \mathrm{~mm}$ in diametro, cum foliis $3 \mathrm{~mm}$ latus, divaricatim furcatus, stolonibus validis. Folia caulina imbricata, subrecte patula, parum concava, margine postico plus minus falcatim recurvo, in plano oblongo-ovata, $1.4 \sim 1.5 \mathrm{~mm}$ longa,

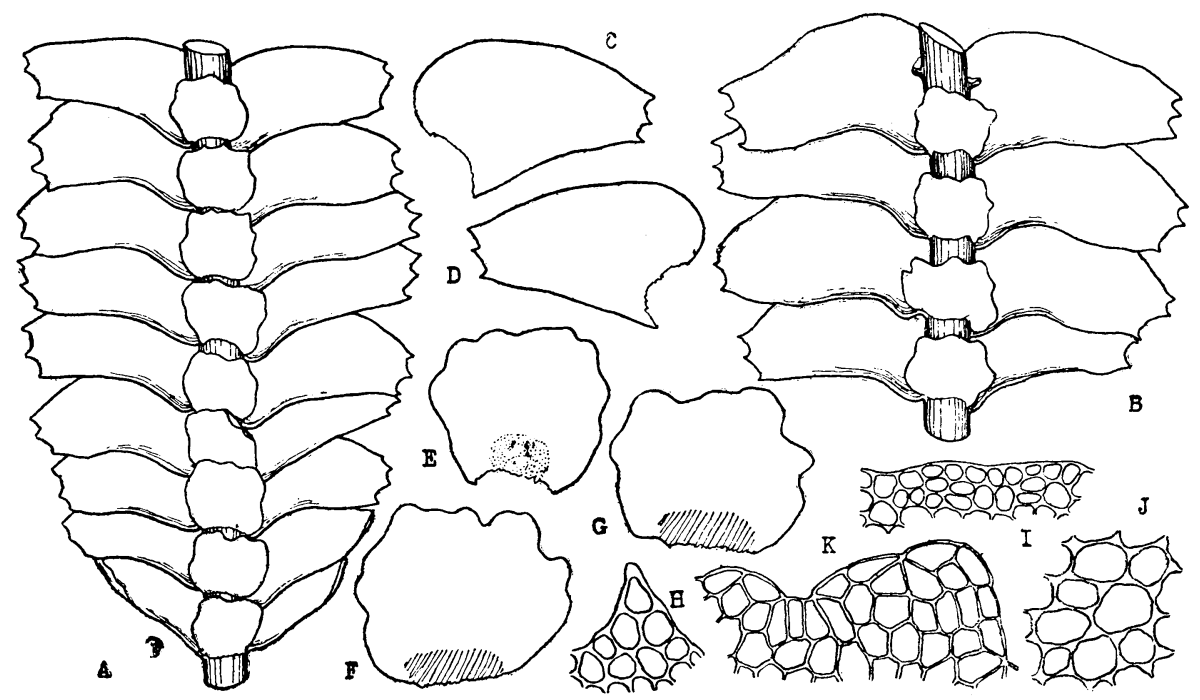

Fig. 21. Bazzania albicans Stephant.

a, b. Partes caulinum, ventrale visae $(\times 16)$. c, d. Folia caulina $(\times 16)$. e-g. Amphigastria caulina $(x 36)$. h. Spina ex apice folii $(x 140)$. i. Cellulae ex margine folii $(\times 140)$. j. Cellulae ex medio folii $(x 140)$. k. Apex amphigastrii $(\times 140)$. (Yoshinaga no. 10: b, f-g, k; no. 29: a, c-c, h-j).

*）本研究は文部省科學研究費により遂行されたものである。 
basi $0.85 \mathrm{~mm}$ lata, apice quam basis duplo angustiore, subrecte truncato, tridentato, dentibus triangulatis, acutis, margine antico arcuato, postico substricto. Cellulae apicales $15 \sim 20 \mu$, dorso-marginales $15 \mu$ in diametro, basales ad $45 \mu$ longae, $25 \mu$ latae, trigonis magnis, acutis. Amphigastria caulina majora, tenera, transverse inserta, appressa, contigua, caule duplo latiora, $0.46 \mathrm{~mm}$ longa, $0.5 \mathrm{~mm}$ lata, subquadrata, apice breviter lobata vel repanda; cellulae amphigastriorum fere hyalinae, rectangulares, leptodermes, basi multo minores, parietibus valde incrassatis, cum chlorophylli granulis obscurae.

Nom. Nippon. Mukadegole (Yoshinaga 1903); Siro-mutigole (YaSUDA 1911).

Spec. exam. Prov. Tosa: Sakawa (Yoshinaga, no. 19, 29, 30, 35, 68, Apr. 1896, det. Stephani) ; Genkôin-yama (Yoshinaga, no. 10, Jul. 1897, det. Stephani, sub Mastigobryo tenuistipulo Steph.).

Distr. Nippon (Honsyû, Sikoku, Kyûsyû, Ryûkyû, Taiwan), China (Kwangsi).

23) Bazzania bidentula Stephani ex YASUda, Syokubutugaku-Kakuron (Inkwa-bu) 711 (1911), nom. nud.; Nicholson in MazzetTi, Symbolae Sinicae V, 23 (1930), sine descr. Fig. 22.

Mastigobryum bidentulum Stepinani in Soc. Sci. Nat. Cherbourg XXIX, 222 (1894); Spec. Hepat. III, 435 (1908).

Planta parva, tenera, fragilis, pallide viridula, aetate fulvescens, in cortice expansa vel aliis hepaticis consociata. Caulis olivaceo-virens, rigidus, ad $2 \mathrm{~cm}$ longus, $0.18 \mathrm{~mm}$ in diametro, cum foliis $1.4 \mathrm{~mm}$ latus, furcatus, apice saepe attenuatus, phyllobolus, flagellis capillaceis. Folia caulina contigua vel parum imbricata, apicibus liberis, subrecte patula, ovato-oblonga, $0.76 \sim 0.83 \mathrm{~mm}$ longa, $0.4 \sim 0.48 \mathrm{~mm}$ lata, apice angustiore, oblique truncato, acuto vel bidentato, raro tridentato, dentibus parvis, inaequalibus, acutis. Cellulae quadratae, apicales $18 \sim 20 \mu$ diametro, basales $35 \sim 40 \times 25 \sim 30 \mu$ metientes, parietibus aequaliter parum incrassatis, trigonis majusculis, acutis. Amphigastria caulina magna, contigua, transverse inserta, subappressa, caule duplo vel magis latiora, e basi paululo angustiore quadrato-rotundata, $0.35 \mathrm{~mm}$ longa, $0.35 \sim 0.4 \mathrm{~mm}$ lata, apice irregulariter repanda, cellulis fere ut in folii.

Nom. Nippon. Hutaba-mutigoke (YASUda 1911).

Spec. exam. Prov. Tosa: in monte Yokogura (Yoshinaga, no. 2, Apr. 1898, det. Stephani) ; prov. Kai: in monte Komagatake (TAmura, no. 24, Aug. 1903, det. Stephani in Herb. Yoshinaga).

Distr. Nippon (Honsyû, Sikoku, ins. Yakusima, Taiwan, Tyôsen), China, Altai, Yunnan. 


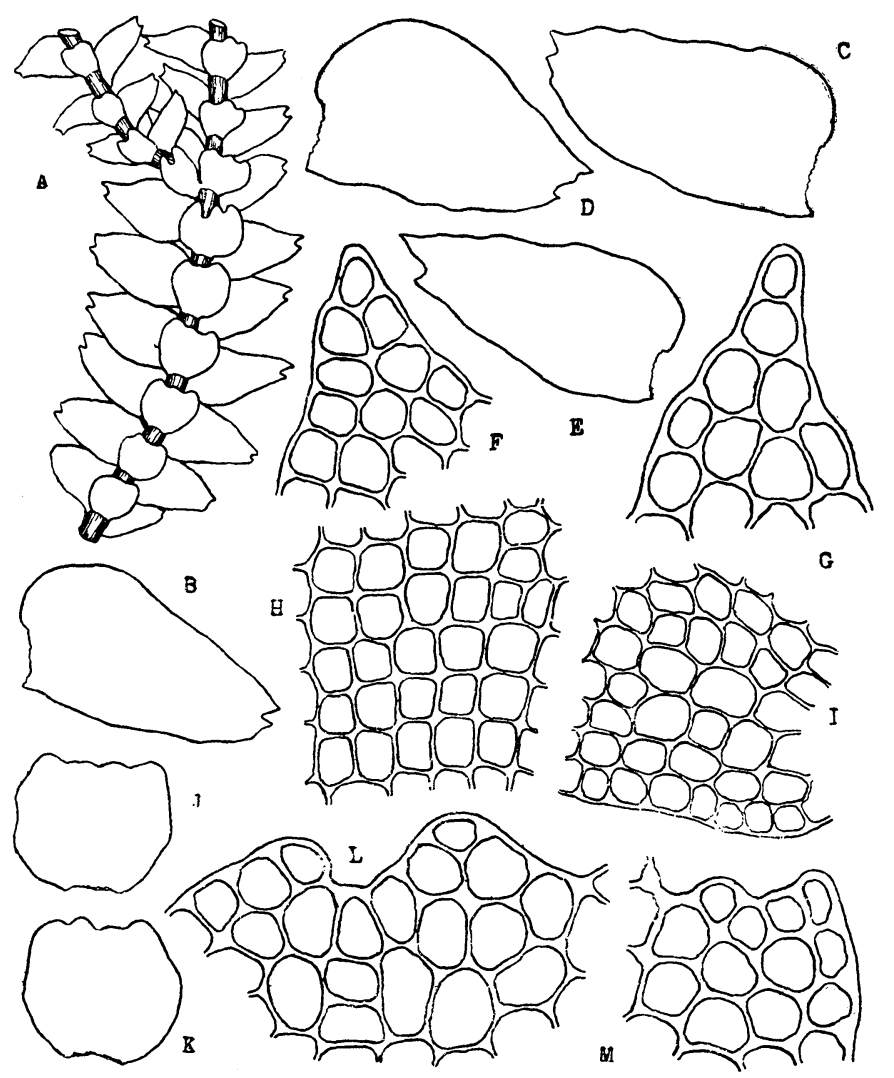

Fig. 22. Bazzania bidentula StтеPHANI.

a. Pars caulis, ventrale visa $(\times 16)$. b-e. Folia caulina $(\times 36)$. f, g. Dentes ex apicibus foliorum $(\times 275)$. h. Cellulae ex medio folii $(\times 275)$. i. Eaedem ex basi folii $(\times 275)$. j, k. Amphigastria caulina $(\times 36)$. 1, m. Apices amphigastriorum $(\times 275)$. (TAMURA no. 24).

24) Bazzania fissifolia Stephani ex Yasuda, l. c., nom. nud. Fig. 23. Mastigobryum fissifolium Stephani ex Yoshinaga in Bot. Mag. Tokyo XX, 53 (1906), sine descr.; Stephani, Spec. Hepat. III, 502 (1908).

Planta mediocris vel minor, fusca, plus minus flaccida, dense caespitans. Caulis brunneus, debilis, ad $3 \mathrm{~cm}$ longus, parum furcatus, flagellis parvis, brevibus (ca. $5 \mathrm{~mm}$ longis). Folia caulina contigua vel parum imbricata, subrecte patula, concava, apice libero, arcte decurvo, saepe hamatim recurvo, in plano ovato-trigona, $1.3 \sim 1.5 \mathrm{~mm}$ longa, basi $0.9 \sim 1 \mathrm{~mm}$ lata, apice profunde tri-(raro quadri-) fida, sinubus angustissimis, acutis, laciniis lanceolatis, attenuatis, irregularibus. Cellulae apicales $18 \mu$ diametro, basales $34 \sim 38 \times 18 \sim 20 \mu$ metientes, trigonis magnis, acutis. Amphigastria caulina magna, sinuatim inserta, caule triplo latiora, reniformia, plus minus 


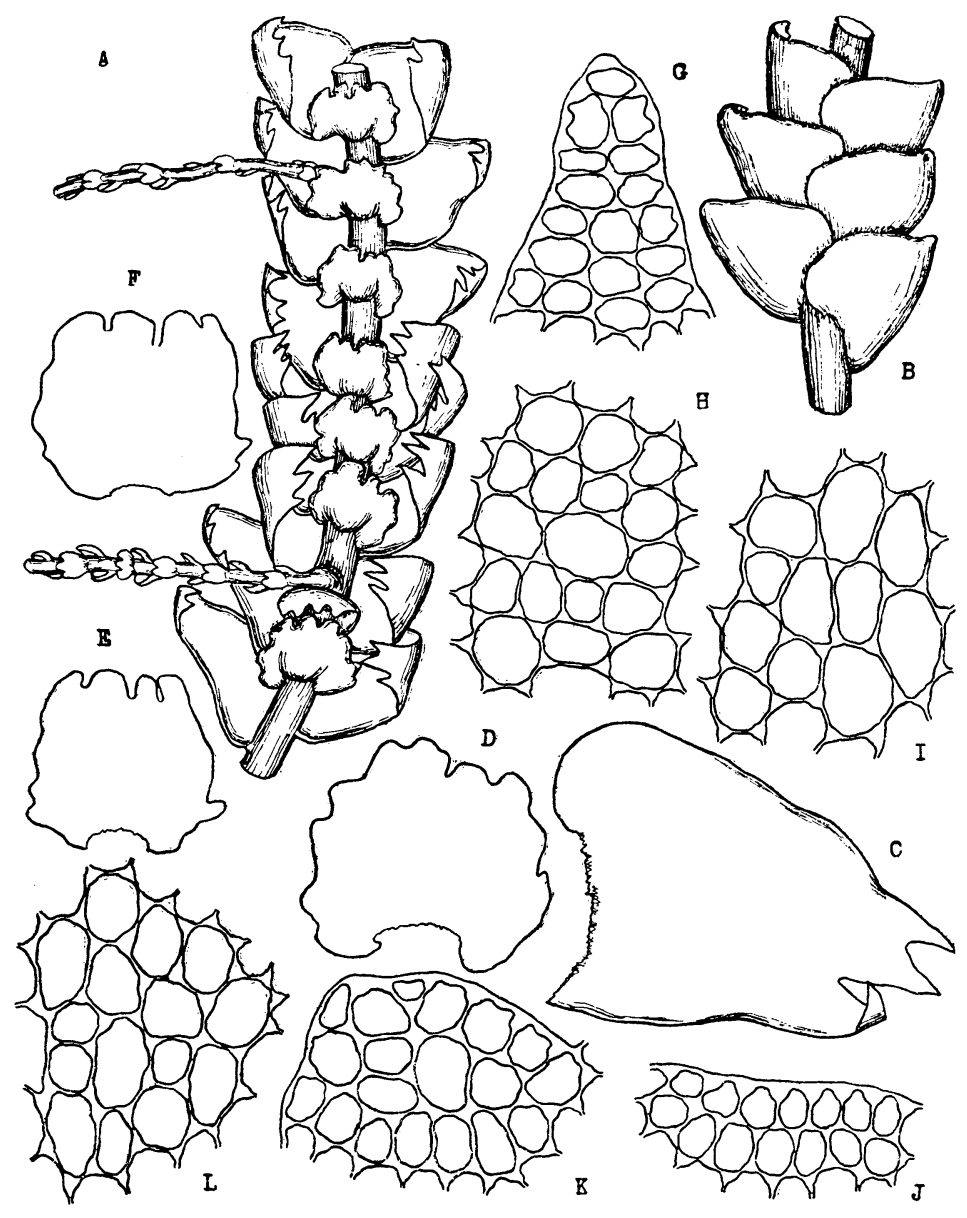

Fig. 23. Bazzania fissifolia Stephani.

a. Pars caulis, ventrale visa $(\times 16)$. b. Eadem, dorsale visa $(\times 16)$. c. Folium caulinum $(\times 36)$. d-f. Amphigastria caulina $(\times 36)$. g. Lacinia folii $(\times 275)$. h. Cellulae ex medio folii $(\times 275)$. i. Eaedem ex basi folii $(x 275)$. j. Eaedem ex margine folii $(\times 275)$. k. Lobus amphigastrii $(\times 275)$. 1. Cellulae ex basi amphigastrii ( $\times 275)$. (TAMURA no. 5).

quadrata, $0.58 \sim 0.6 \mathrm{~mm}$ longa, $0.6 \sim 0.66 \mathrm{~mm}$ lata, apice subtruncato, $0.36 \sim$ $0.4 \mathrm{~mm}$ lato, irregulariter inciso-lobato, lobis obtusis, integerrimis, cellulis ut in folii.

Nom. Nippon. Sakeba-mutigoke (YASUdA 1911); Sakeha-mukadegoke (Ihsiba 1930).

Spec. exam. Prov. Kai: in monte Komagatake (K. Tamura, no. 5, Aug. 1903, det. Stephani in Herb. T. Yoshinaga, no. 42).

Distr. Nippon (Honsyû, ins. Yakusima, Taiwan). 
25) Bazzania fissifolia var. subsimplex (Stephani in sched.) S. HAtтori, stat. nov. Fig. 24.

Mastigobryum subsimplex Stephani in sched.

Planta minor, flavo-brunnea vel fuscata, dense caespitosa. Caulis brunneus, ad $4 \mathrm{~cm}$ longus, $0.2 \mathrm{~mm}$ in diametro, cum foliis $1 \mathrm{~mm}$ latus, subsimplex, flagellis parvis, brevibus (ad $4 \mathrm{~mm}$ longis), radicellis e basi amphigastriorum ortis, plus minus fasciculatis. Folia caulina remota, raro

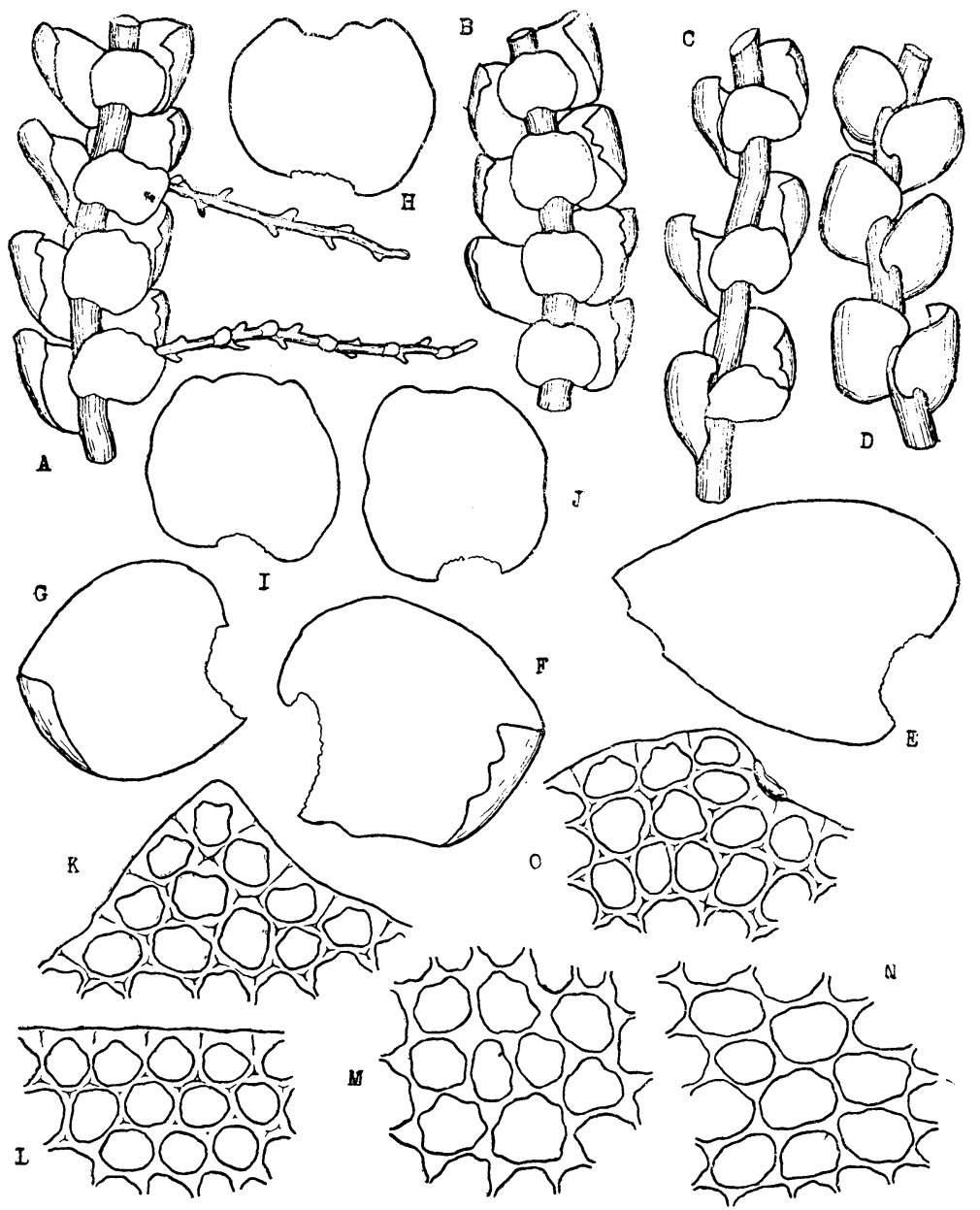

Fig. 24. Bazzania fissifolia var. subsimples (StePH. in sched.) S. HATTORI. a-c. Partes caulinum, ventrale visae $(\times 16)$. d. Eadem, dorsale visa $(\times 16)$. e-g. Folia caulina $(\times 36)$. h-j. Amphigastria caulina $(x 36)$. k. Dens folii $(\times 275)$. 1. Cellulae ex margine folii $(\times 275)$. $\mathrm{m}$. Cellulae ex medio folii $\times 275)$. n. Eaedem ex basi folii $(\times 275)$. o. Apex amphigastrii $(\times 275)$. (TAMURA no. 12) 
contigua, parum oblique patula, valde concava, apice arcte decurva, in plano trigono-ovata, $0.9 \mathrm{~mm}$ longa, basi $0.66 \mathrm{~mm}$ lata, apice quam basis multo angustiora, oblique truncata, acuta vel breviter bi- vel tridenticulata. Cellulae apicales $18 \sim 20 \mu$, mediae $25 \mu$ diametro, basales $30 \sim 32 \times 25 \mu$ metientes, parietibus validis, trigonis maximis. Amphigastria caulina remota, magna, caule duplo vel magis latiora, subtransverse inserta, reni-

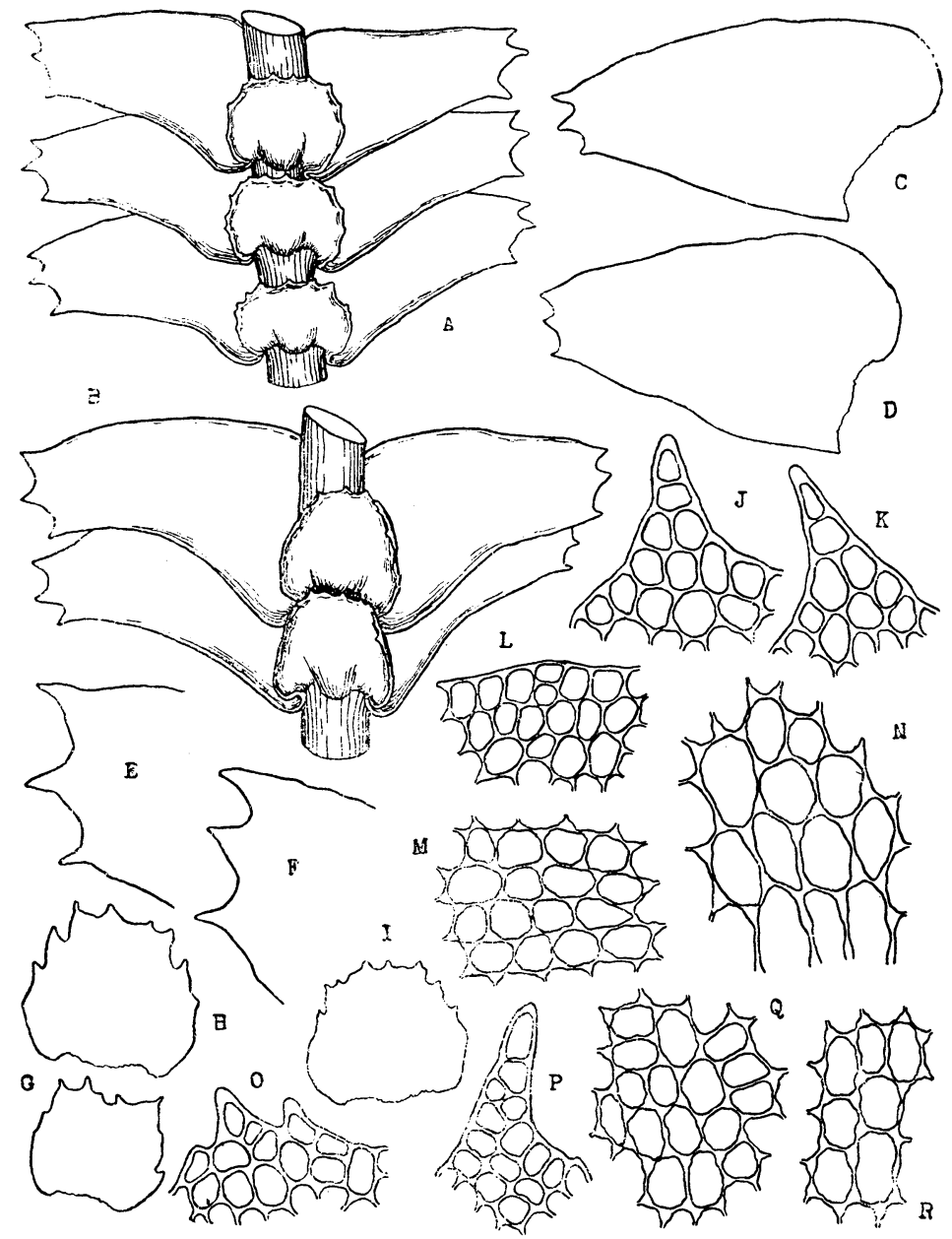

Fig. 25. Bazzania flavo-virens StтPHANI.

a, b. Partes caulinum, ventrale visae $(\times 16)$. c, d. Folia caulina $(\times 16)$. e, $f$. Apices foliorum $(\times 36)$. g-i. Amphigastria caulina $(\times 16)$. j,k. Dentes foliorum $(x 140)$. l. Cellulae ex margine folii $(\times 140)$. m. Eaedem ex medio folii $(\times 140)$. n. Eaedem ex basi folii $(\times 140)$. o, p. Dentes amphigastriorum $(\times 140)$. q. Cellulae ex medio amphigastrii $(x 140)$. r. Eaedem ex basi amphigastrii $(\times 140)$. (Yoshinaga no. 59). 
formia, plus minus quadrata, $0.56 \mathrm{~mm}$ longa et lata, apice subtruncata, brevissime lobata, lobis integerrimis, cellulis ut in folii.

Nom. Nippon. Hoso-mutigoke (nov.).

Spec. exam. Prov. Kai : in monte Komagatake (Tamura, no. 12, Aug. 1903-Co-typus in Herb. Yoshinaga no. 43).

Distr. Endemica.

26) Bazzania flavo-virens Stephan in Bull. Herb. Boiss. V, 86 (1897). Fig. 25.

Mastigobryum flavo-virens Stephani, Spec. Hepat. III, 452 (1908).

Planta major, flavo-virens, dense caespitans. Caulis ad $12 \mathrm{~cm}$ longus, iterum furcatus, crassus, flagellis longis, numerosis. Folia caulina imḅricata, apicibus liberis, subrecte patula, valde decurva, in plano trigono-ovata, asymmetrica, $2 \sim 2.2 \mathrm{~mm}$ longa, basi $1.4 \mathrm{~mm}$ lata, apice oblique truncata,

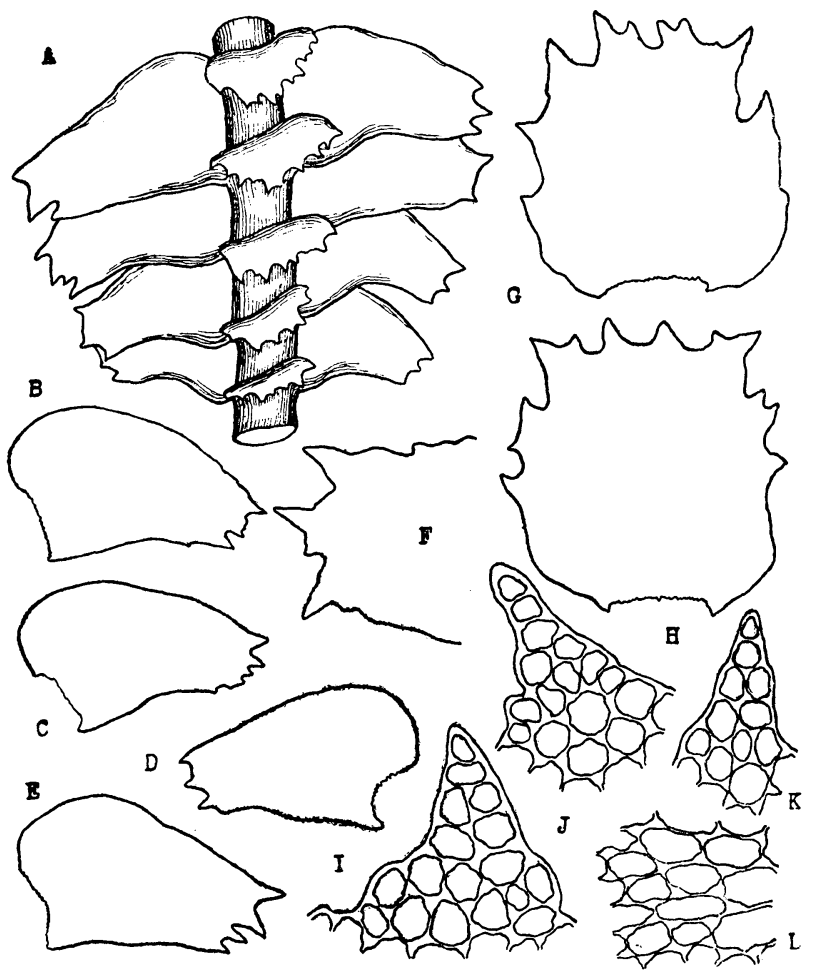

Fig. 26. Bazzania japonica (SDE. LAa.) LINDB.

a. Pars caulis, ventrale visa $(\times 16)$. b-e. Folia caulina $(\times 16)$. f. Apex folii $(x 36)$. g, h. Amphigastria caulina $(x 36)$. i. Dens folii $(x 140)$. $\mathrm{j}, \mathrm{k}$. Dentes amphigastriorum $(\times 140)$. l. Cellulae ex basi amphigastrii $(\times 140)$. (Yoshinaga no. 25). 
tridentata, $0.4 \sim 0.5 \mathrm{~mm}$ lata, dentibus angustis, acutis, sinubus lunatis. Cellulae apicales $24 \sim 28 \mu$ in diametro, trigonis parvis, acutis, basales $56 \sim$ $62 \times 32 \sim 36 \mu$ metientes, trigonis magnis, acutis. Amphigastria caulina sinuatim inserta, uno latere folio adjacente minuteque connata, caule duplo latiora, margine anguste recurva, in plano subquadrata, $0.8 \sim 0.9 \mathrm{~mm}$ longa, $1 \sim 1.1 \mathrm{~mm}$ lata, apice subtruncata, $5 \sim 8$-dentata, dentibus acuminatis, acutis, cellulis ut in folii.

Nom. Nippon. Moegi-mutigoke (YASUdA 1911); Moegi-mukadegoke (Ihsiba 1930).

Spec. exam. Prov. Tosa: Sakawa-mati (Yoshinaga, no. 59, Apr. 1896 -Co-typus).

Distr. Japonia (Honsyû, Sikoku).

27) Bazzania japonica (Sande Lacoste) Lindberg in Acta Soc. Sci. Fenn. X, 224 (1872). Fig. 26, 27.

Mastigobryum japonicum Sande Lacoste in Miquel, Ann. Mus. Bot. Lugd.-Bat. I, 303, Tab. VIII, f. 1-4 (1863-64).

Planta mediocris, viridi-olivacea, dense depresso-caespitosa. Caulis brunneo-virens vel fuscus, ad $6 \mathrm{~cm}$ longus, $0.3 \mathrm{~mm}$ in diametro, cum foliis $2 \sim 2.8 \mathrm{~mm}$ latus, regulariter furcatus, flagellis plus minus numerosis, longiusculis. Folia caulina imbricata, decurva, subrecte patula, apicibus liberis, in plano ovato-oblonga, $1 \sim 1.7$ $\mathrm{mm}$ longa, basi $0.6 \sim 0.9 \mathrm{~mm}$ lata, plus minus falcata, apice quam basis duplo angustiore, parum oblique truncato, tridentato, dentibus validis, triangulatis, acutis, porrectis, sinubus subacutis, irregularibus. Cellulae apicales $22 \sim 27 \mu$ in diametro, basales $40 \sim 50 \times 26 \sim 30 \mu$ metientes, trigonis magnis, acutis. Amphigastria caulina majora, saepe foliis utrinque brevissime coalita, subquadrata, caule duplo latiora, $0.44 \sim 0.7 \mathrm{~mm}$ longa, $0.54 \sim 0.7$ $\mathrm{mm}$ lata, apice arcte recurvo, varie lobato, lobis brevibus et obtusis sed

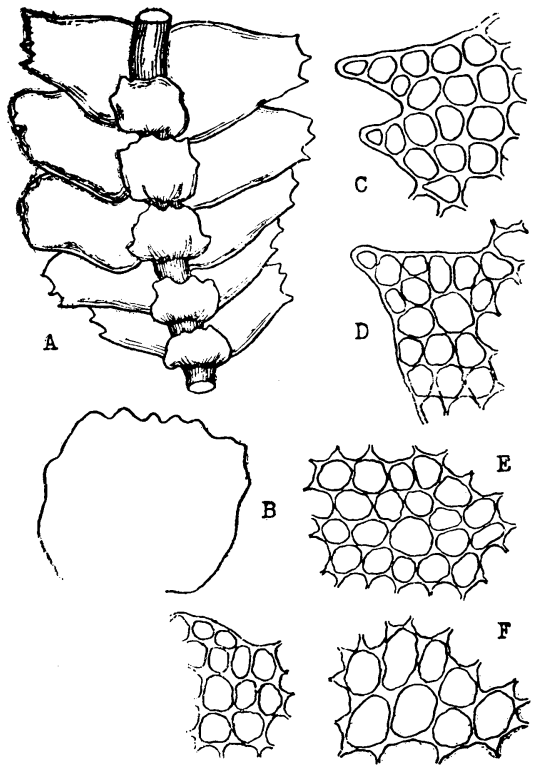

Fig. 27. Bazzania japonica (SDE. Lac.) LindB.

a. Pars caulis, ventrale visa $(\times 16)$.

b. Amphigastrium caulinum $(\times 36)$. c, d. Dentes foliorum $(x 140)$. e. Cellulae ex medio folii $(x 140)$. f. Eaedem ex basi folii $(\times 140)$. g. Apex amphigastrii $(\times 140)$. (YoshinaGA no. 8). 
saepius validis et acutis, vel angulato-dentatis, lateralibus breviter obtuseque lobata vel angulata acuta; cellulae ut in folii.

Nom. Nippon. Yamato-mukadegoke (IHsiBa 1930).

Spec. exam. Prov. Tosa: in monte Yokogura (Yoshinaga, no. 8, Apr. 1896), Sakawa-mati (Yoshinaga, no. 25, Apr. 1896).

Distr. Japonia (Honsyû, Sikoku, Kyûsyû).

28) Bazzania tenuistipula Stephani ex YASUdA, Syokubutu-gaku Kakuron (Inkwa-bu) 711 (1911), nom. nud. Fig. 28.

Mastigobryum tenuistipulum Stephani ex Inoue in Bot. Mag. Tokyo XII, 211 (1898), sine descr.; Stephani, Spec. Hepat. III, 466 (1908).

Planta minor, flavo-virens, flaccida, in aetate brunnescens, depressocaespitosa. Caulis ad $4 \mathrm{~cm}$ longus, $0.28 \mathrm{~mm}$ in diametro, fuscus, debilis, regulariter breviuscule furcatus, flagellis parvis. Folia caulina parum imbricata, recte patula, plano-disticha, in plano oblonga, vix falcata, 1.4 1.45 $\mathrm{mm}$ longa, basi $0.7 \sim 0.75 \mathrm{~mm}$ lata, apice duplo angustiore, $0.3 \mathrm{~mm}$ lato, subrecte truncato, tridentato, dentibus triangulatis, acutis. Cellulae apicales $18 \sim 24 \mu$ in diametro, trigonis parvis, basales $34 \sim 40 \times 26 \sim 28 \mu$ metientes, trigonis magnis, acutis. Amphigastria caulina contigua vel remota, caule duplo latiora, transverse inserta, appressa, subquadrata, circumcira breviter repanda, $0.4 \sim 0.5 \mathrm{~mm}$ longa, $0.4 \sim 0.48 \mathrm{~mm}$ lata; cellulae ubique leptodermes, rectangulatae, hyalinae.

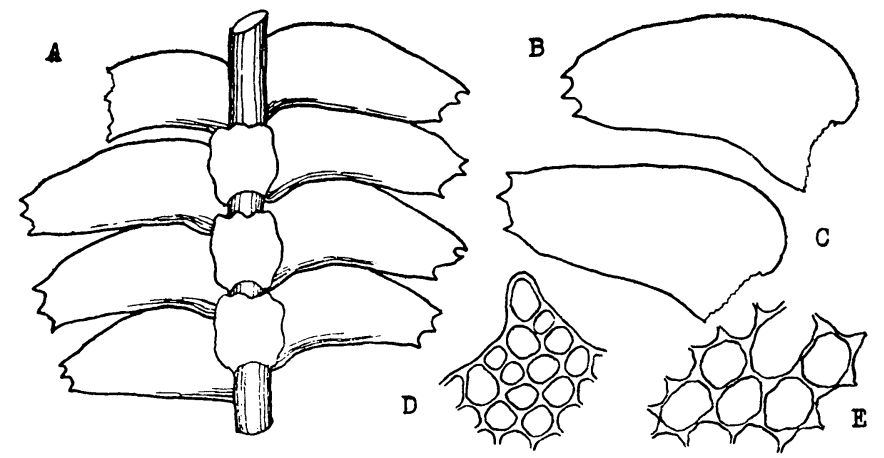

Fig. 28. Bazzania tenuistipula StEPHANI.

a. Pars caulis, ventrale visa $(\times 18)$. b, c. Folia caulina $(\times 18)$. d. Dens folii apicalis $(\times 155)$. e. Cellulae ex basi folii $(\times 155)$. (Yoshinaga no. 41$)$.

Nom. Nippon. Hime-mutigoke (YASUda 1911).

Spec. exam. Prov. Tosa : Kitahara-mura, Hukuda (Yoshinaga, no. 41, Jun. 1900, det. Stephani, sub B. ceylanica).

Distr. Japonia (sine loco speciali). 
29) Bazzania Yoshinagana StePhani ex YASUdA, Syokubutu-gaku Kakuron (Inkwa-bu) 711 (1911), nom. nud. Fig. 29.

Mastigobryum Yoshinaganum Stephani ex Yoshinaga in Bot. Mag. Tokyo XX, 53 (1906), sine descr.; Stephani, Spec. Hepat. III, 490 (1908).

Planta magna, robusta, olivaceo-viridis, in aetate fuscescens, dense caespitans. Caulis ad $5 \mathrm{~cm}$ longus, $0.6 \mathrm{~mm}$ im diametro, crassus, virens, regulariter longeque furcatus, flagellis validis sed brevibus. Folia caulina dense imbricata, recte patula, paululo decurva, in plano oblonga, vix falcata, $2.5 \sim 3.2 \mathrm{~mm}$ longa, basi $1.5 \sim 1.7 \mathrm{~mm}$ lata, apice recte truncata, $0.7 \sim 0.9 \mathrm{~mm}$ lata, tridentata, dentibus triangulatis, brevioribus. Cellulae apicales $20 \sim$

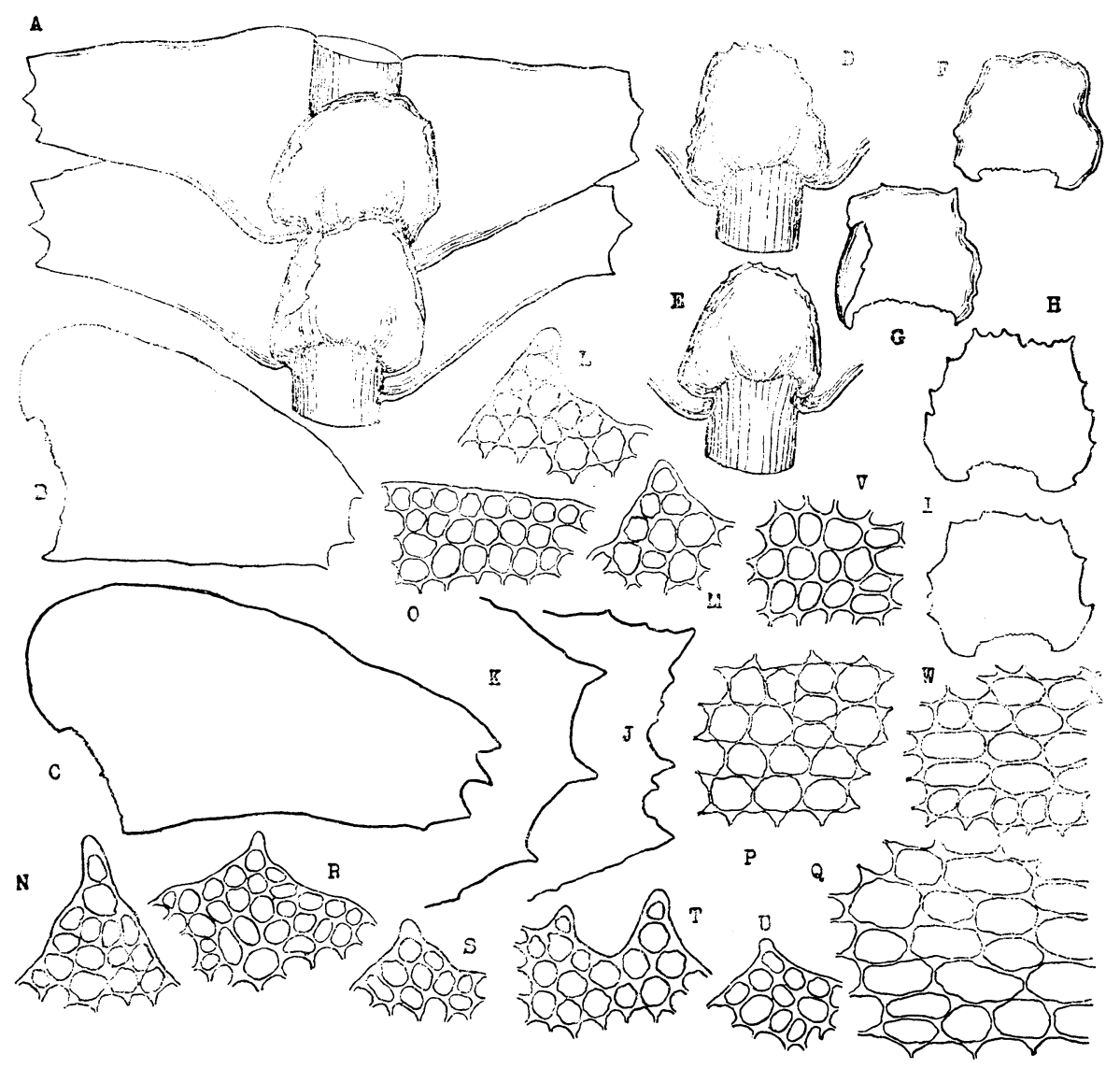

Fig. 29. Bazzania Yoshinagana StePHANI.

a. Pars caulis, ventrale visa $(\times 16)$. b, c. Folia caulina $(\times 16)$. d-i. Amphigastria caulina $(x 16)$. j, k. Apices foliorum $(\times 36)$. l-n. Dentes foliorum $(\times 140)$. o. Cellulae ex margine folii $(\times 140)$. p. Eaedem ex medio folii $(x 140)$. q. Eaedem ex basi folii $(\times 140)$. r-u. Dentes amphigastrii $(\times 140)$. v. Cellulae ex medio amphigastrii $(\times 140)$. w. Eaedem ex basi amphigastrii ( $\times 140$ ). (TAMURA no. 39). 
$22 \mu$ in diametro, mediae $34 \sim 40 \times 28 \mu$, basales $48 \sim 54 \times 28 \mu$ metientes, trigonis magnis, acutis vel nodulosis. Amphigastria caulina magna, caule duplo latiora, parum imbricata, subtransverse inserta, margine arcte minuteque recurva, in plano subquadrata, $0.9 \sim 0.95 \mathrm{~mm}$ longa, $1 \sim 1.1 \mathrm{~mm}$ lata, circumcirca irregulariter dentata, dentibus parvis, acutis, cellulis ut in folii.

Nom. Nippon. Yosinaga-mutigoke (YASUda 1911).

Spec. exam. Prov. Kai : in monte Komagatake (Tamura, no. 4, no. 39, Aug. 1903-Original. det. Stephani in Herb. Yoshinaga no. 39 et no. 38).

Distr. Endemica.

\section{摘要}

\section{服部新佐旦本座苔類研究其四}

本號に於て汒本邦産ムチゴケ屬（Bazzania）中未だ圖示せられず，及その記載も 原記相文の外殆ど見るへきものつない種若干を報告する。本研究に使用した標本は 總て吉永虎馬氏 (高知市) の所藏せられるものである。今包筆者のとひ應じて貴 重なる標本全部を貸與された同氏に深く謝意を表する。

22）ムカデゴケの原記相文は極端な形に 基いて與へられたがその後種としての 範圍を擴げられたものである。相當に變化に富む種であつて中部以南の山麓地帶に 普通炕分布する。

23）フタバムチゴケは亞高山地帶の樹皮に普通である。蔡上部の葉は屢々脫落 して腹葉のみを殘す。小形の明瞭な種である。

24）サケバムチゴケの原記載は部分的に見られる特徽が一般的なものとして而 も幾分誇張されてねるやうである。日本の高山乃至亞高山の岩場に稍普通に見られ る種で非常に變化に富むものである。

25）ホりムチゴケ (新稱) は STEPHANI 未發表の 1 種であるが, 篗者は之を前 述サケバムチゴケの細長なる一變種とした。本邦の高山に於て同種を多量に探集研 究したが，基準種と本變種間には種々の中間的な形が存在するやうである。

26) モエギムチゴケの原標本は STEPHANI の原記載文末尾忙 Inouë 59 とある 通り本研究に使用したもの〉一牛であるが, STEPHANI は之を Bazzania semiconnata STEPH. と同定してなる。多分初め該種に含め，後之を新種之認めたものであらう。 ての事實壮吉永虎馬氏も既に氣附んてをられ筆者に綿密なる書簡を賜はつた。茲に 厚くその好意を謝する。

27）ヤマトムチゴケは本邦の中部以南に普通なる一種である。本號に扱つたム チゴケ中既に圖のある唯一の種であるが，SANDE LACOSTE の原記相文及び同圖共に 
極めて不滿足のものであつてその正體を確實にする事は困難である。よつて本研究 に於ては主として STEPHANI の記相文に賴つた次第である。

28）ヒメムチゴケは主に山麓地帶に生育する小形の苔である。一體ムチゴケ屬 の分類には腹葉の構造並びに形狀が大いに手掛りとなるものであるが、本種及びシ ロムチゴケは腹葉の細胞が薄膜透明なる一群に屬し, 腹葉の細胞が葉細胞同樣に葉 綠粒を含み不透明にして角隅の肥厚せる他の一群に對するものである。

佾本種は一方ではシロムチゴケ，他方では B. ceylanica (MitT.) NICHOLS. なる 2 個の大きな種の中間を占める小さい種と考へられる。

29）ヨシナガムチゴケは本邦の深山に生ずる强大なるムチゴケである。STEPHANI の原記相文に於て本種及びサケバムチゴケは吉永氏探集となつてるるが，實 は田村氏が探集して吉永氏に送附し，吉永氏が之を STEPHANI に途つたものであ る。

東京科學博物館植物學部 